\title{
Autopercepción de la alfabetización informacional en estudiantes de una escuela de arte
}

\author{
Self-perception of information literacy in students of an art school
}

Autopercepção da alfabetização da informação em estudantes de escolas de arte

\author{
Liliana Ivonne Espinoza-Salazar \\ lespi2164gmail.com \\ https://orcid.org/0000-0002-6336-4771 \\ Universidad César Vallejo, Piura-Perú
}

\author{
Hildegardo Oclides Tamariz-Nunjar \\ hiltanun@gmail.com \\ https://orcid.org/0000-0002-4512-6120 \\ Universidad César Vallejo, Piura-Perú
}

Artículo recibido 18 de agosto 2021, arbitrado y aceptado 23 de septiembre 2021 y publicado 17 de diciembre 2021

\section{RESUMEN}

Actualmente se requiere que las personas se vuelvan actores especializados en el acceso a la información, y resulta imperiosa la necesidad de adquirir habilidades en alfabetización informacional. El artículo tiene como objetivo conocer el nivel de alfabetización informacional de los estudiantes de una escuela de arte. La metodología asume un diseño no experimental, desarrolla un tipo de investigación de campo de nivel descriptivo y transversal, La población estuvo conformada por los estudiantes matriculados en el primer semestre de la Escuela de Arte "Ignacio Merino" de Piura, Perú, y la muestra constituida por 69 estudiantes. Los resultados muestran un nivel regular de alfabetización informacional en el $100 \%$ de los estudiantes de una escuela de arte, siendo los estudiantes del género masculino en un $24 \%$ que reportan más dificultad en el acceso, utilización y evaluación de la información a diferencia de las estudiantes de género femenino.

Palabras clave: Necesidad de información; Gestión de la información; Evaluación de la información
ABSTRACT

RESUMO
Currently, people are required to become specialized actors in access to information, and the need to acquire skills in information literacy is imperative. The article aims to know the information literacy level of the students of an art school. The methodology assumes a nonexperimental design, develops a type of descriptive and cross-sectional field research. The population was made up of students enrolled in the first semester of the "Ignacio Merino" Art School in Piura, Peru, and the sample made up of 69 students. The results show a regular level of information literacy in $100 \%$ of the students of an art school, with 24\% being male students who report more difficulty in accessing, using and evaluating information than in the female students.

Key words: Information needs; Information management; Information evaluation; Information needs
Hoje em dia, as pessoas são obrigadas a se tornar atores especializados no acesso à informação, e a necessidade de adquirir habilidades de alfabetização da informação é imperativa. O objetivo deste artigo é descobrir o nível de alfabetização dos alunos de uma escola de arte. A metodologia assume um desenho não experimental, desenvolvendo um tipo descritivo e transversal de pesquisa de campo. A população consistia de alunos matriculados no primeiro semestre da Escola de Arte "Ignacio Merino" em Piura, Peru, e a amostra consistia de 69 alunos. Os resultados mostram um nível regular de alfabetização de informação em 100\% dos estudantes de uma escola de arte, com $24 \%$ dos estudantes masculinos relatando mais dificuldade de acesso, utilização e avaliação da informação do que as estudantes femininas.

Palavras-chave: Necessidade de informação; Gestão da informação; Avaliação da informação; Literacia da informação; Literacia da informação 


\section{INTRODUCCIÓN}

El desarrollo de la sociedad y de los avances tecnológicos han demandado en las personas la necesidad de contar con la capacidad de buscar, procesar información y crear conocimiento (Martín, 2018). La alfabetización informacional (ALFIN) representa un aspecto esencial en el desarrollo de los diversos campos e inclusive en la solución de crisis internacionales (Byrne, 2005).

El origen de la ALFIN se ubica en los setenta del siglo pasado y se le atribuye a Paul Zurkowski (Zurkowski, 1974). En este sentido existen diversas aproximaciones conceptuales respecto a la ALFIN, sus posturas han evolucionado a través de los años donde los cuestionamientos en el campo educativo versan en torno a su pertinencia, utilidad y enfoque para el aprendizaje y que han variado debido al contexto de adelantos tecnológicos permitiendo una flexibilización en sus definiciones (Ramírez y Fernández, 2018; Mitchell, 2007; Torres, 2018).

Para la investigación, se entiende ALFIN como la capacidad para identificar la necesidad de la información, gestionar la búsqueda, evaluarla, así como reconocer su importancia, pudiendo ser en formato impreso, digital o electrónico de igual manera utilizarla de forma crítica se y eficiente. Además, se considera la responsabilidad ética de los usuarios para utilizar la información en la producción de conocimiento (ACRL, 2015; Martín, 2018; Kurbanoglu, Akkoyunlu, y Umay, 2006).

Al revisar la producción científica de la ALFIN a nivel internacional, se encuentra que, entre los años 2005 a 2015 Estados Unidos y Canadá fueron los países que más realizaron investigaciones en torno al tema, seguido de Europa, Asia y África; en estas regiones, el $80 \%$ de los estudios se orientaron a medir el nivel de alfabetización informacional en el nivel superior. De la misma en América Latina, Torres (2018) señala que las investigaciones realizadas en ALFIN tanto en Brasil como Colombia se orientan a revisiones teóricas que consideran adaptaciones de propuestas internacionales más que trabajos empíricos, pero en el ámbito de las instituciones de educación superior falta profundizar en este tema (Uribe, 2010).

En Perú, un estudio empírico destaca los resultados significativos de un programa ALFIN en el ámbito de la salud (Huaillani, 2020). En el campo educativo, la ALFIN está orientado hacia el aprendizaje, más que la gestión y uso de información (Gómez, 2018). En esta perspectiva, Ferrés, Aguaded y García-Matilla (2012) mencionan que las administraciones educativas deben asumir el compromiso de alfabetizar en el uso de la información colaborando de esta manera con la competencia mediática asumida por la Organización de Naciones Unidas (UNESCO, 2014), quien al respecto considera entre los tres frentes de actuación enunciados en la «Orientación Normativa Estratégica de la Alfabetización Mediática e Informacional» que las instituciones educativas deben desarrollar propuestas curriculares en torno a esta necesidad generalizada.

Por su parte Huaillani (2020) en su programa de ALFIN demostró mejoras significativas en las dimensiones: reconocimiento de las necesidades de información (79.28\%), elaboración de estrategia de búsqueda, selección y recuperación de información (73.91\%), uso ético en el acceso a la información para la elaboración de las investigaciones (72.96\%), uso de gestores de referencias bibliográficas para la elaboración de las investigaciones (86.96\%) entre 
el grupo control y el grupo experimental. También Mears-Delgado y Marzal (2018) midieron el impacto de Evalfin, un modelo de evaluación integral de la alfabetización información para las instituciones de educación superior y determinaron un nivel de competencia alto en docentes y estudiantes que participaron en alguna actividad del programa a diferencia de los que no habían asistido.

Los jóvenes de los tiempos actuales son hábiles en el manejo tecnológico de aparatos y software y su interés digital se reduce a la aplicación de algún servicio web o aplicación, pero carecen de habilidades de pensamiento y de capacidades críticas. Siendo la alfabetización informacional un pilar fundamental en la formación de los estudiantes y elemental en la era digital Bruce (1997), resulta necesario que el estudiante desarrolle habilidades para el manejo adecuado de la información (Toledo y Maldonado-Radillo, 2015).

La pregunta que formula el problema de investigación es la siguiente: ¿Cuál es el nivel de alfabetización informacional que presentan los estudiantes de una escuela de arte? La presente investigación pretende determinar el nivel de alfabetización informacional en los estudiantes regulares de una escuela de arte, los resultados ayudarán a proponer estrategias metodológicas para mejorar sus habilidades, así como la calidad de sus aprendizajes.

\section{MÉTODO}

El estudio asume un diseño no experimental, y según Palella Stracuzzi y Martins Pestana (2010) este es aquel según el cual el investigador manipula una variable experimental no comprobada bajo condiciones controladas, asi mismo se desarrolla un tipo de investigación de campo de nivel descriptivo y transversal, para Salkind (1998) la investigación descriptiva presenta las características del hecho analizado. Es tranversal porque se recoge información en un solo momento dado (Bernal, 2010).

La investigación se realizó en una escuela de arte de gestión pública ubicada en la zona urbana de la ciudad de Piura, Perú, en el primer semestre del 2020. La Escuela de Arte "Ignacio Merino" de Piura, es una institución con rango universitario que forma artistas profesionales en distintas especialidades, así como profesores de arte, forma parte de las 22 escuelas a nivel nacional (Ministerio de Educación, 2011). Hasta la fecha, en la institución no se han llevado a cabo actividades curriculares que promuevan el desarrollo de la ALFIN, en razón a ello se determinó desarrollar una investigación que identificara el nivel de alfabetización informacional de los estudiantes realizando un diagnóstico que permita reflejar las debilidades en torno a la ALFIN y plantear una propuesta desde el currículo.

La población corresponde a todos los estudiantes matriculados en el primer semestre. La muestra estuvo constituida por 69 estudiantes, el $52 \%$ correspondían al I ciclo, 25\% al III ciclo, 9\% al V ciclo y el $14 \%$ al IX ciclo. Asimismo, el $48 \%$ pertenecieron al sexo masculino y el $52 \%$ al sexo femenino, Las edades oscilan entre los 19 y 28 años. Todos los encuestados cumplieron como criterios de inclusión estar matriculados, participar de forma voluntaria y llenar la totalidad de ítems de la encuesta.

El instrumento fue un cuestionario diseñado y validado por Toledo y Maldonado-Radillo (2015) para medir las competencias informacionales en instituciones de educación superior. El cuestionario estuvo conformado por 21 enunciados sobre la base 
de cinco dimensiones: capacidad para determinar la información, utilización de la información, evaluación dela información, acceso a la información y necesidad de información y se autoadministró de forma virtual. El cuestionario presenta una escala de Likert de cinco puntos para determinar los niveles con el siguiente rango de evaluación: Nivel bajo:1-2, nivel regular: 3-4 y nivel alto: 5. Para corroborar la consistencia del cuestionario, se obtuvo un alfa de Cronbach de 0,949.

La recolección de los datos se efectuó al final del I ciclo a través de Google form, los estudiantes recibieron el enlace vía virtual. Con los datos obtenidos se construyó una base de datos. Dada la naturaleza de la investigación, los datos fueron expresados en promedios y desviación estándar. Los datos fueron analizados con el paquete estadístico IBM SPSS Statistics 22.

\section{RESULTADOS Y DISCUSIÓN}

En la Tabla 1, se presenta el promedio $\mathrm{y}$ desviación estándar de las puntuaciones por cada ítem recogido en los 69 cuestionarios aplicados sobre alfabetización informacional. Los ítems que tuvieron mayor puntuación fueron "Soy capaz de sacar conclusiones basadas en la información obtenida", "Manejo las funciones básicas de los procesadores de texto, hojas de cálculo, Power Point para desempeñar mis actividades laborales (Microsoft Word, Open Office, MS Word para Mac)" y "Sé cómo utilizar computadora de escritorio (PC), laptop, impresoras y escáneres en mis actividades laborales" con promedios de $3,9 \pm 0,8 ; 3,9 \pm 1$ y $4 \pm 1$ respectivamente. Por su parte, los ítems con menor puntaje fueron "Construyo una estrategia de búsqueda utilizando los comandos apropiados del sistema de recuperación de información elegido (por ej.: operadores Booleanos, truncamiento y proximidad para los motores de búsqueda; organizadores internos, como los índices para libros)" e "Indago la opinión de expertos utilizando entrevistas, correo electrónico, servidores de listas de correo, etc.) para verificar la información recuperada" con cifras similares de $3 \pm 1$ en cada caso.

Tabla 1. Puntuación asignada a cada ítem del cuestionario de alfabetización informacional.

\begin{tabular}{ll}
\hline \multicolumn{1}{c}{ VARIABLE } & $\%$ \\
\hline Reconozco que el uso de información primaria y secundaria varía según las diferentes disciplinas & $3,6 \pm 0,9$ \\
Amplio el proceso de búsqueda y obtención de imágenes, videos, texto, o sonido & $3,8 \pm 0,9$ \\
$\begin{array}{l}\text { Reviso la necesidad inicial de información para aclarar, reformar o refinar mi búsqueda acerca del tema } \\
\text { a investigar }\end{array}$ & $3,8 \pm 0,8$ \\
$\begin{array}{l}\text { Se identificar palabras claves, sinónimos y términos relacionados para poder accesar a la información } \\
\text { que necesito }\end{array}$ & $3,7 \pm 0,8$ \\
\hline
\end{tabular}


Soy capaz de resumir las ideas principales de los resultados encontrados

Organizo la información recuperada para la elaboración de un tema o realizar una actividad (ejemplo

Integro la información obtenida, incluyendo citas y paráfrasis, de forma que apoye la finalidad del tema o la actividad

Puedo elaborar un informe, con los principales resultados encontrados para cubrir con los requerimientos del trabajo encargado.

Manejo las funciones básicas de los procesadores de texto, hojas de cálculo, Power Point para desempeñar mis actividades laborales (Microsoft Word, Open Office, MS Word para Mac)

Construyo una estrategia de búsqueda utilizando los comandos apropiados del sistema de recuperación de información elegido (por ej.: operadores Booleanos, truncamiento y proximidad para los motores de búsqueda; organizadores internos, como los índices para libros).

Utilizo diferentes motores de búsqueda, directorios, recursos electrónicos y meta-buscadores para accesar a

la información que necesito

Valoro la cantidad, calidad y relevancia de los resultados de la búsqueda realizada para un tema para determinar si necesito utilizar otro sistema de recuperación de información

Soy capaz de diferenciar entre fuentes de información primaria y secundaria

Sé cómo se produce, organiza y difunde la información necesaria para realizar mi investigación acerca de un tema

Indago la opinión de expertos utilizando entrevistas, correo electrónico, servidores de listas de correo, etc.) para verificar la información recuperada

Puedo identificar el valor y las diferencias entre los recursos disponibles en una gran variedad de formatos

(por ej., multimedia, bases de datos, páginas web, conjunto de datos, audiovisuales, libros, etc.)

Examino y comparo la información recuperada de varias fuentes para evaluar su fiabilidad y validez

Puedo determinar si la necesidad original de información ha sido satisfecha o si se requiere información adicional

${ }^{*}$ Datos expresados en promedio \pm desviación estándar. 
En la Tabla 2, al comparar los resultados según el sexo, en la dimensión capacidad para determinar la información se encontró que los varones tienen mayor puntuación en "Soy capaz de resumir las ideas principales de los resultados encontrados" con promedios $3,7 \pm 0,8$ y un menor puntaje en "Se identificar palabras claves, sinónimos y términos relacionados para poder accesar a la información que necesito" con promedio de $3,5 \pm 0,8$. En el caso de las mujeres, la mayor puntuación se ubica en "Amplio el proceso de búsqueda y obtención de imágenes, videos, texto, o sonido" y menor promedio en "Reconozco que el uso de información primaria y secundaria varía según las diferentes disciplinas" con $4,1 \pm 0,9$ y $3,6 \pm 1$ respectivamente.

Tabla 2. Puntuación asignada a cada ítem en la dimensión capacidad para determinar la información.

\section{DIMENSIÓN CAPACIDAD PARA DETERMINAR LA INFORMACIÓN}

$\%$

HOMBRE

$3,6 \pm 0,7$

$3,5 \pm 0,9$

$4,1 \pm 0,9$

Amplio el proceso de búsqueda y obtención de imágenes, videos, texto, o sonido.

$3,7 \pm 0,7$

$3,9 \pm 0,9$

Reviso la necesidad inicial de información para aclarar, reformar o refinar mi búsqueda acerca del tema a investigar.

Se identificar palabras claves, sinónimos y términos relacionados para poder accesar a la información que necesito.

$3,5 \pm 0,8$

$3,8 \pm 0,8$

Soy capaz de resumir las ideas principales de los resultados encontrados.

$3,7 \pm 0,8$

$3,9 \pm 0,8$

${ }^{*}$ Datos expresados en promedio \pm desviación estándar.

En la Tabla 3, se observa que en la dimensión utilización de la información los alumnos presentan menor puntuación en "Puedo elaborar un informe, con los principales resultados encontrados para cubrir con los requerimientos del trabajo encargado". De la muestra estudiada, las mujeres tuvieron mejor puntuación $(3,3 \pm 1)$ que los varones $(3,3 \pm 0,9)$.

Tabla 3. Puntuación asignada a cada ítem en la dimensión acceso a la información.

\section{DIMENSIÓN ACCESO A LA INFORMACIÓN}

$\%$

HOMBRE

$3,6 \pm 0,7$

$3,6 \pm 1$

Construyo una estrategia de búsqueda utilizando los comandos apropiados del sistema de recuperación de información elegido (por ej.: operadores Booleanos, truncamiento y proximidad para los motores de búsqueda; organizadores internos, como los índices para libros).

Utilizo diferentes motores de búsqueda, directorios, recursos electrónicos y meta-buscadores para accesar a la información que necesito.

Valoro la cantidad, calidad y relevancia de los resultados de la búsqueda realizada para un tema para determinar si necesito utilizar otro sistema de recuperación de información.

$\%$ MUJER

*Datos expresados en promedio \pm desviación estándar. 
En la Tabla 5, se observa que en la dimensión necesidad de información los alumnos presentan menor puntuación en "Indago la opinión de expertos utilizando entrevistas, correo electrónico, servidores de listas de correo, etc.) para verificar la información recuperada”. De la muestra estudiada, los varones tuvieron mejor puntuación $(3,1 \pm 0,8)$ que las mujeres $(3 \pm 1,2)$.

Tabla 5. Puntuación asignada a cada ítem en la dimensión necesidad de información.

\begin{tabular}{|c|c|c|}
\hline DIMENSIÓN NECESIDAD DE INFORMACIÓN & $\begin{array}{c}\% \\
\text { HOMBRE }\end{array}$ & $\begin{array}{c}\% \\
\text { MUJER }\end{array}$ \\
\hline Soy capaz de diferenciar entre fuentes de información primaria y secundaria. & $3,4 \pm 0,8$ & $3,8 \pm 0,9$ \\
\hline $\begin{array}{l}\text { Sé cómo se produce, organiza y difunde la información necesaria para realizar mi investigación } \\
\text { acerca de un tema. }\end{array}$ & $3,6 \pm 0,7$ & $4 \pm 0,7$ \\
\hline $\begin{array}{l}\text { Indago la opinión de expertos utilizando entrevistas, correo electrónico, servidores de listas de } \\
\text { correo, etc. para verificar la información recuperada. }\end{array}$ & $3,1 \pm 0,8$ & $3 \pm 1,2$ \\
\hline
\end{tabular}

En la Tabla 6, se observa que en la dimensión evaluación de la información los alumnos presentan menor puntuación en "Puedo determinar si la necesidad original de información ha sido satisfecha o si se requiere información adicional". De la muestra estudiada, las mujeres tuvieron mejor puntuación $(3,7 \pm 0,9)$ que los varones $(3,4 \pm 0,8)$.

Tabla 6. Puntuación asignada a cada ítem en la dimensión evaluación de la información.

\begin{tabular}{|c|c|c|}
\hline DIMENSIÓN CAPACIDAD PARA DETERMINAR LA INFORMACIÓN & HOMBRE & MUJER \\
\hline $\begin{array}{l}\text { Puedo identificar el valor y las diferencias entre los recursos disponibles en una gran variedad } \\
\text { de formatos (por ej., multimedia, bases de datos, páginas web, conjunto de datos, audiovisuales, } \\
\text { libros, etc.) }\end{array}$ & $3,6 \pm 0,9$ & $3,8 \pm 1$ \\
\hline $\begin{array}{l}\text { Examino y comparo la información recuperada de varias fuentes para evaluar su fiabilidad y } \\
\text { validez. }\end{array}$ & $3,4 \pm 0,9$ & $3,8 \pm 0,9$ \\
\hline $\begin{array}{l}\text { Puedo determinar si la necesidad original de información ha sido satisfecha o si se requiere } \\
\text { información adicional. }\end{array}$ & $3,4 \pm 0,8$ & $3,7 \pm 0,9$ \\
\hline $\begin{array}{l}\text { Comunico la información obtenida con claridad para cumplir con los requerimientos del } \\
\text { trabajo encargado }\end{array}$ & $3,7 \pm 0,9$ & $3,8 \pm 0,7$ \\
\hline $\begin{array}{l}\text { Sé cómo utilizar computadora de escritorio (PC), laptop, impresoras y escáneres en mis } \\
\text { actividades laborales }\end{array}$ & $3,8 \pm 1$ & $4,2 \pm 0,9$ \\
\hline
\end{tabular}

${ }^{\star}$ Datos expresados en promedio \pm desviación estándar. 
En las dimensiones: capacidad para determinar la información (Tabla 2), utilización de la información (Tabla 3), acceso a la información (Tabla 4), necesidad de información (Tabla 5), evaluación de la información (Tabla 6) se observa que el género femenino obtuvo mayor puntuación en los promedios respecto a los estudiantes del género masculino. Los promedios más altos obtenidos por los estudiantes del género masculino se ubican en los ítems: Soy capaz de sacar conclusiones basadas en la información obtenida $(3,8 \pm 0,8)$; manejo las funciones básicas de los procesadores de texto, hojas de cálculo, PowerPoint para desempeñar mis actividades laborales (Microsoft Word, Open Office, MS Word para Mac) $(3,8 \pm 1)$ y sé cómo utilizar computadora de escritorio (PC), laptop, impresoras y escáneres en mis actividades laborales $(3,8 \pm 1)$.

El estudio tuvo como propósito determinar el nivel de la ALFIN que tienen los estudiantes regulares de una escuela de arte. Los resultados muestran que los estudiantes tienen un promedio que varía entre 3-4 puntos y que los ubica en el nivel regular de ALFIN, por lo que saben reconocer básicamente la fuente de información, reconocen su necesidad de información y pueden resumir ideas, pero tienen limitaciones en el proceso de búsqueda especialmente utilizando palabras claves. También infieren conclusiones, organizan la información, manejan comúnmente los procesadores de textos, pero tienen dificultades para hacer uso de citas y elaborar los informes. Por otro lado, utilizan algunos motores de búsqueda, pero presentan limitaciones en el uso de comandos para recuperar información. También identifican los recursos disponibles en la web, pero tienen dificultades para evaluar su calidad. En los tiempos actuales, toda persona debe saber gestionar la información, además de utilizarla de forma adecuada (Martín, 2018).

Los promedios que oscilan entre 1 y 2 puntos identificados como nivel bajo se reportan en las dificultades para utilizar los comandos apropiados del sistema de recuperación de información, uso de palabras claves para buscar información, y formas de verificación de la información. Esto pudiera deberse a una formación pobre en los niveles educativos (Gross y Latham, 2012; Kim y Shumaker, 2015). En este sentido, los resultados coinciden con el estudio de Mears-Delgado y Marzal (2018) en su estudio con estudiantes de educación superior donde los estudiantes que no participaron de una capacitación presentaron un nivel de competencia bajo.

Asimismo, los resultados refieren que las estudiantes son las que presentan mejores puntuaciones en promedios que oscilan entre 3,3 a 4,2a diferencia de los estudiantes varones, esto podría deberse a las características personales y los estilos de aprendizaje.

\section{CONCLUSIONES}

Los resultados muestran un nivel regular de alfabetización informacional en el 100\% de los estudiantes de una escuela de arte, siendo los estudiantes del género masculino en un $24 \%$ que reportan más dificultad en el acceso, utilización y evaluación de la información a diferencia de las estudiantes de género femenino.

Se recomienda desarrollar una propuesta metodológica que promueva desde las asignaturas específicas del plan de estudios de la escuela de arte la formación en ALFIN para potenciar la formación desde el ingreso de los estudiantes (Gross y Latham, 
2012; Kim y Shumaker, 2015), siendo un reto para las instituciones educativas, considerando que es una competencia mediática de todo ciudadano según la UNESCO (2014). Asimismo, desarrollar investigaciones en capacidades tecnológicas que complementen el conocimiento inicial de ALFIN. Finalmente, se puede extender el estudio a todos los estudiantes de la escuela de arte, y, también en otras escuelas de arte a nivel nacional para comparar el nivel de ALFIN en estas instituciones de formación artística.

\section{REFERENCIAS}

ACRL. (02 de Febrero de 2015). Framework for Information Literacy for Higher Education. Recuperado el 12 de Junio de 2021, de http:// www.ala.org/acrl/standards/ilframework

Bernal, C. (2010). Metodología de la investigación. Tercera edición. Colombia: Pearson Educación.

Bruce, B. (1997). "Literacy Technologies: What Stance Should We Take?". Journal of Literacy Research. 29(2) , 289-309

Byrne, A. (2005). La Alfabetización Informacional desde una Perspectiva Global: El Desastre Agudiza Nuestras Mentes. Anales de Documentación, 87 (20)

Gómez, A. (2018). Trends and methodological approaches in the research on information literacy: 2005-2015. Opción 34(87), 1341-1369.

Gross, M., y Latham, D. (2012). What's skill got to do with it?: Information literacy skills and self-views of ability among first-year college students. . Journal of the American Society for Information Science and Technology 63(3), 574-583

Huaillani, S. (2020). Influencia de un programa de alfabetización para el desarrollo de habilidades informativas en los profesionales de un instituto pediátrico. Revista Cubana de Información en Ciencias de la Salud, 31(1) , 1-19

Kim, S., y Shumaker, D. (2015). Student, librarian, and instructor perceptions of information literacy instruction and skills in a first year experience program: A case study. . The Journal of Academic Librarianship, 41(4) , 449-456

Kurbanoglu, S., Akkoyunlu, B., y Umay, A. (2006). Developing the information literacy self-efficacy scale. Journal of Documentation, 62(6) , 730743

Martín, V. (2018). Information literacy and neoliberal library: Towards a new paradigm. Información,Cultura y Sociedad, 39, 129-138.

Mears-Delgado, B., y Marzal, M. (2018). EVALFIN: UN MODELO DE EVALUACIÓN DE ALFABETIZACIÓN INFORMACIONAL PARA INSTITUCIONES DE EDUCACIÓN SUPERIOR. . El profesional de la información, 27(4)

Ministerio deEducación.(2011).Diseño de currículo experimental para la carrera profesional de profesor de Educación Artística,especialidad Artes Visuales. Lima: MINEDU

Mitchell, E. (2007). Organization as Metaliteracy: Evaluating student use of metadata and information organization principles in the classroom. Paper presented at the SIG-CR workshop at ASISyT 2007

Palella Stracuzzi, S., y Martins Pestana, F. (2010). Metodologia de la Investigación Cuantitativa. Carcas, Venezuela: FEDUPEL, Fondo Editorial de la Universidad Pedagógica Experimental Libertador

Ramírez, R., y Fernández, M. (2018). Diagnóstico de habilidades en alfabetización informacional de los profesionales de la Biblioteca Nacional de Cuba. Bibliotecas anales de investigación , 68-82

Toledo, M., y Maldonado-Radillo, S. (2015). Alfabetización informacional en instituciones de educación superior: diseño de un instrumento de medición $\mathrm{N}^{\circ} 60$. Biblios , 14-31

Torres, A. (2018). Tendencias y acercamientos metodológicos en investigaciones sobre alfabetización informacional: 2005 - 2015. Opción 87, 1341-1369

UNESCO. (2014). Orientación normativa y estratégica de la alfabetización mediática e informacional. Recuperado el 12 de Junio 
de 2021, de http://unesdoc.unesco.org/ images/0019/001929/192971e.pdf

Uribe, A. (2010). La alfabetización informacional en Iberoamérica. Una aproximación a su pasado, presente y futuro desde el análisis de la literatura publicada y recursos web. Revista de Sistemas de Información y Documentación (IBERSID). $4,165-175$
Zurkowski, P. (1974). The Information Service Environment Relationships and Priorities. Related Paper No. 5. [Washington, D.C.]. Washington, DC.: Distributed by ERIC Clearinghouse 